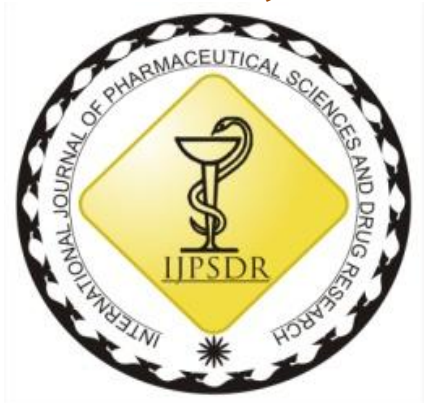

ISSN: 0975-248X

Research Article CODEN (USA): IJPSPP

(cc) BY-NC-SA

\title{
Selective Cytotoxic Activity of Synthetic Natural Cyclopeptides on HCT11 \& B16F10 Cells
}

\author{
Kaushal K. Chandrul' ${ }^{\text {, Rajiv Dahiya }}{ }^{2}$, Sunil Singh ${ }^{1 *}$ \\ ${ }^{1}$ Department of Pharmaceutical Chemistry, Faculty of Pharmaceutical Sciences, Mewar University, NH-79, Gangrar, \\ Chhitorgarh-312901, Rajasthan, India \\ ${ }^{2}$ Department of Pharmaceutical Chemistry, School of Pharmacy, Faculty of Medical Sciences, The University of the West \\ Indies, St. Augustine, Trinidad \& Tobago, WI
}

Copyright (C) 2018 Kaushal K. Chandrul et al. This is an open access article distributed under the terms of the Creative Commons Attribution-NonCommercial-ShareAlike 4.0 International License which allows others to remix, tweak, and build upon the work noncommercially, as long as the author is credited and the new creations are licensed under the identical terms.

\begin{abstract}
Peptides are natural messenger molecules of human body and hence ideal lead compounds for the initiation of drug discovery research. They are the important organic compounds with potent biological activities. Peptides functions as hormones, enzymes enzyme inhibitors, or substrates or growth inhibitors or promoters, neurotransmitters and immunomodulators. Investigation of new and more potent analogs of molecules with already established activities from a key part of research in pharmaceutical field. It's brings many modifications by manipulates the parent molecules structures serves to increase the activity of the compound, also eliminate adverse effect or toxicity associated with the parent drug. Cancer is the leading cause of deaths in world, We evaluated four natural cyclopeptides Diandrine A, Diandrine C, Fanlizhicyclopeptide A, Fanlizhicyclopeptide B, for cytotoxicity against HCT116 (Human Colorectal Carcinoma) \& B16F10 (musculus skin melanoma) cells.
\end{abstract}

Keywords: Cyclopeptides, synthesis, cell line, HCT116, B16F10.

DOI: 10.25004/IJPSDR.2018.100608

Int. J. Pharm. Sci. Drug Res. 2018; 10(6): 480-486

*Corresponding author: Mr. Sunil Singh

Address: Department of Pharmaceutical Chemistry, Faculty of Pharmaceutical Sciences, Mewar University, NH-79, Gangrar, Chhitorgarh312901, Rajasthan, India

Tel.: +91-8224874888

E-mail $\bowtie$ : rssunil29@gmail.com

Relevant conflicts of interest/financial disclosures: The authors declare that the research was conducted in the absence of any commercial or financial relationships that could be construed as a potential conflict of interest.

Received: 09 September, 2018; Revised: 20 October, 2018; Accepted: 06 November, 2018; Published: 20 November, 2018

\section{INTRODUCTION}

Plants are a major part of healthcare system in general and always rich in components with greater biological properties. ${ }^{[1-2]}$ Over $70 \%$ population of the world follow traditional medicine, mostly based on plant remedies. The natural products from medicinal plants, either as pure compounds or as standardized extracts, provide unlimited opportunities for development of new drug leads molecules because of the unmatched availability of chemical diversity. [3-6] Plant-derived cyclopolypeptides play a vital role in drug discovery and drug design and have provided significant results for future study. [7-10] They have complex structures with modified amino acid moieties and are associated with a number of pharmacological activities including antimicrobial activity [11], tyrosinase inhibitory activity 
[12], anti-inflammatory activity [13], antimalarial activity [14], protease inhibitory activity [15], antioxidant and anticancer activity. [16] Only minute quantities of cyclopeptides obtained from natural resources restricted researchers to investigate their biological profiles in detail. Keeping in view broad spectrum of bioactivities exhibited by these natural congeners and in order to obtain a potent bioactive compound in good yield [17-18], present investigation was directed toward in-vitro cell line study on synthesized some natural cyclopeptides.

\section{MATERIALS AND METHODS}

Melting point was determined by open capillary method and was uncorrected. L-Amino acids and other chemicals used were obtained from Spectrochem Limited (Mumbai, India). IR spectra were recorded on Shimadzu 8700 FTIR spectrophotometer (Shimadzu, Japan) and ${ }^{1} \mathrm{H}$ and ${ }^{13} \mathrm{C}$ NMR spectra were recorded on Bruker AC NMR spectrometer (Bruker, USA) at 300 MHz. FAB-MS was recorded on JMS-DX 303 Mass spectrometer (Jeol, Tokyo, Japan) operating at $70 \mathrm{eV}$ from School of Pharmaceutical Education and Research, Jamia Hamdard University. Purity of all compounds was checked by TLC on precoated silica gel $G$ plates using mixture of chloroform and methanol in different ratios (9:1 intermediate linear peptides and 7:3 for cyclopeptide). Standard MTT assay was used to evaluate cell line viability in the presence of extracts with HCT116 and B16F10 cells.

Synthesis of Natural Cyclopeptides

All linear peptides $(0.005 \mathrm{~mol})$ were deprotected at carboxyl end using $\mathrm{LiOH}(0.18 \mathrm{~g}, 0.0075 \mathrm{~mol})$ in THF: $\mathrm{H}_{2} \mathrm{O}(1: 1)$ to get Boc-amino acids-OH. The deprotected peptide unit $(0.005 \mathrm{~mol})$ was now dissolved in $\mathrm{CHCl}_{3}$ $(50 \mathrm{~mL})$ at $0^{\circ} \mathrm{C}$. To the above solution, pentafluorophenol $(1.23 \mathrm{~g}, 0.0067 \mathrm{~mol})$ and DIPC (0.63 $\mathrm{g}, 0.005 \mathrm{~mol}$ ) was added and stirred at RT for $12 \mathrm{~h}$. The reaction mixture was filtered and the filtrate was washed with $10 \% \mathrm{NaHCO}_{3}$ solution $(2 \times 25 \mathrm{~mL})$ and $5 \%$ $\mathrm{HCl}(3 \times 15 \mathrm{~mL})$ to get the corresponding fluorophenyl ester Boc-Amino acids-O-pfp. To this compound (0.004 $\mathrm{mol})$ dissolved in chloroform $(25 \mathrm{~mL})$, trifluoroacetic acid $(0.91 \mathrm{~g}, 0.008 \mathrm{~mol})$ was added, stirred at RT for $1 \mathrm{~h}$ and washed with $10 \% \mathrm{NaHCO}_{3}$ solution $(3 \times 20 \mathrm{~mL})$. The organic layer was dried over anhydrous $\mathrm{Na}_{2} \mathrm{SO}_{4}$ to get Amino acids-O-pfp which was dissolved in $\mathrm{CHCl}_{3}$ (25 $\mathrm{mL})$ and TEA/NMM/pyridine $(2.8 \mathrm{~mL} / 2.21$ $\mathrm{mL} / 1.61 \mathrm{~mL}, 0.02 \mathrm{~mol})$ was added. Then, whole content was kept for 1 week time at $0^{\circ} \mathrm{C}$. The reaction mixture was washed with $10 \% \mathrm{NaHCO}_{3}$ and $5 \% \mathrm{HCl}$ solutions $(3 \times 25 \mathrm{~mL})$. The organic layer was dried over anhydrous $\mathrm{Na}_{2} \mathrm{SO}_{4}$. Finally, chloroform was distilled off and crude cyclized product was crystallized from $\mathrm{CHCl}_{3} / n$-hexane to get pure cyclopeptides.

\section{Diandrine A}

Yellowish needles, m.p. $135-137^{\circ} \mathrm{C}$, Yield $79.8 \%$ (NMM), $70.3 \%$ (TEA), 66.8\% $\left(\mathrm{C}_{5} \mathrm{H}_{5} \mathrm{~N}\right),[\alpha]_{\mathrm{D}}:-67.8^{\circ}$ $\left.67.6^{\circ}\right), \mathrm{R}_{\mathrm{f}}-0.59$; IR (KBr): $v 3472$ (m, -NH str, indole ring), 3375 (m/br, -OH str, Tyr), 3129-3125, 3121 (m, $\mathrm{NH}$ str, amide), 3078, 3069-3062 (w, -CH str, aromatic rings), 2998-2992 (m, -CH str, cyclic $\mathrm{CH}_{2}$ and $\left.\mathrm{CH}\right), 2926$, 2922, 2917 (m, -CH str, asym, $\mathrm{CH}_{2}$ ), 2846, 2837-2833 (m, -CH str, sym, $\mathrm{CH}_{2}$ ), 1679-1675, 1640, 1634-1629 (s, -C=O str, $3^{\circ}$ and $2^{\circ}$ amide), 1560, 1557, 1436-1427 (m, skeletal bands, aromatic rings), 1539, 1535-1532 (m, -NH bend, $2^{\circ}$ amide), 718, 698-692 (s, - $\mathrm{CH}$ bend, oop, aromatic rings) $\mathrm{cm}^{-1} ;{ }^{1} \mathrm{H}$ NMR (300 $\left.\mathrm{MHz} \mathrm{CDCl}_{3}\right): \delta 9.89(1 \mathrm{H}, \mathrm{br}$. s, -NH, Tyr), 9.72 (1H, br. s, -NH, Trp), 7.75 (1H, br. s, $\mathrm{NH}$, Phe), $7.47(2 \mathrm{H}$, br. s, $-\mathrm{NH}$, indole ring and $-\mathrm{OH}$, Tyr), 7.38-7.36 $(1 \mathrm{H}, \mathrm{d}, J=7.75 \mathrm{~Hz}, \alpha-\mathrm{H}$, indole ring), 7.25-7.23 $(1 \mathrm{H}, \mathrm{d}, J=7.3 \mathrm{~Hz}, \gamma-\mathrm{H}$, indole ring), 7.21-7.15 (4H, m, m-H's, Tyr and Phe), 7.14-7.05 (3H, m, $\delta-\zeta-\mathrm{H}^{\prime} \mathrm{s}$, indole ring), 7.02-6.99 (1H, t, $J=6.15 \mathrm{~Hz}, \mathrm{p}-\mathrm{H}, \mathrm{Phe}), 6.91$ (1H, br. s, -NH, Gly), 6.88-6.84 (2H, dd, $J=8.55,5.3 \mathrm{~Hz}$, o-H's, Tyr), 6.83-6.79 (2H, dd, $J=8.8,4.15 \mathrm{~Hz}, \mathrm{o}-\mathrm{H}^{\prime} \mathrm{s}$, Phe), 5.65-5.61 (1H, q, J = 5.6 Hz, $\alpha-\mathrm{H}$, Phe), 5.30-5.28 $\left(2 \mathrm{H}, \mathrm{d}, J=4.75 \mathrm{~Hz}, \mathrm{CH}_{2}, \mathrm{Gly}\right), 4.62-4.58(1 \mathrm{H}, \mathrm{q}, J=6.2$ $\mathrm{Hz}, \alpha-\mathrm{H}, \operatorname{Trp}), 4.25-4.21$ (1H, q, J = 7.85 Hz, $\alpha-\mathrm{H}$, Tyr), 3.92-3.89 $(1 \mathrm{H}, \mathrm{t}, J=6.9 \mathrm{~Hz}, \alpha-\mathrm{H}$, Pro-2), 3.87-3.84 $(1 \mathrm{H}, \mathrm{t}$, $J=6.75 \mathrm{~Hz}, \alpha-\mathrm{H}$, Pro-1), 3.26-3.23 (2H, t, $\delta-\mathrm{H}^{\prime} \mathrm{s}$, Pro-2), 3.21-3.18 (2H, t, $\delta-H^{\prime}$ 's, Pro-1), 2.89-2.87 (2H, d, J = 5.65 $\left.\mathrm{Hz}, \beta-\mathrm{H}^{\prime} \mathrm{s}, \mathrm{Trp}\right), 2.72-2.63$ (4H, m, $\beta$-H's, Pro-1 and Pro2), 2.59-2.57 (2H, d, $\left.J=5.45 \mathrm{~Hz}, \beta-\mathrm{H}^{\prime} \mathrm{s}, \mathrm{Tyr}\right), 2.43-2.41$ $\left(2 \mathrm{H}, \mathrm{d}, J=5.85 \mathrm{~Hz}, \beta-\mathrm{H}^{\prime} \mathrm{s}, \mathrm{Phe}\right), 1.89-1.82\left(4 \mathrm{H}, \mathrm{m}, \gamma-\mathrm{H}^{\prime} \mathrm{s}\right.$, Pro-1 and Pro-2) ppm; ${ }^{13} \mathrm{C}$ NMR $\left(\mathrm{CDCl}_{3}, 300 \mathrm{MHz}\right): \delta$ 173.5, 172.0 (C=O, Pro-1 and Pro-2), 169.9, 169.3 (C=O, Tyr and Trp), 163.1, 162.3 (C=O, Gly and Phe), 154.4 (pC, Tyr), 137.3 ( $\gamma-C$, Phe), 135.9 ( $\alpha^{\prime}-C$, indole ring), 132.2 ( $\gamma-\mathrm{C}, \mathrm{Tyr}), 129.8$ (2C, o-C's, Tyr), 128.9 (2C, o-C's, Phe), 128.1 (2C, m-C's, Tyr), 127.4 (2C, m-C's, Phe), 127.0 ( $\beta^{\prime}-$ $\mathrm{C}$, indole ring), 126.1 (p-C, Phe), 123.3, 121.7 ( $\alpha-\mathrm{C}$ and $\varepsilon$ $C$, indole ring), $119.8,118.5$ ( $\delta-C$ and $\gamma-C$, indole ring), 111.2, 109.6 ( $\beta-C$ and $\zeta-C$, indole ring), 59.2 ( $\alpha-C$, Pro-2), $57.4(\alpha-C$, Pro-1), $57.8(\alpha-C, \operatorname{Trp}), 54.5(\alpha-C$, Tyr), 53.0 ( $\alpha-\mathrm{C}$, Phe), $49.7\left(\mathrm{CH}_{2}, \mathrm{Gly}\right), 48.0,46.9$ ( $\delta-\mathrm{C}^{\prime} \mathrm{s}$, Pro-2 and Pro-1), 41.5 ( $\beta-C$, Phe), 39.6 ( $\beta-C$, Tyr), 30.3 ( $\beta-C$, Pro- 2$)$, 27.8 ( $\beta$-C, Pro-1), 27.0 ( $\beta-\mathrm{C}$, Trp), 25.2, 22.7 (2C, $\gamma-\mathrm{C}^{\prime} \mathrm{s}$, Pro-1 and Pro-2) ppm; FAB-MS: $m / z 748.8(\mathrm{M}+\mathrm{H})^{+}$, 720.8 (748.8-CO) ${ }^{+}, 691.8$ (Pro-Trp-Pro-Tyr-Phe) ${ }^{+}, 663.8$ $(691.8-\mathrm{CO})^{+}, \quad 651.7 \quad$ (Tyr-Phe-Gly-Pro-Trp) ${ }^{+}, \quad 623.7$ (651.7-CO) ${ }^{+}, 601.6$ (Gly-Pro-Trp-Pro-Tyr)+, 594.6 (TrpPro-Tyr-Phe) ${ }^{+}, \quad 585.6$ (Phe-Gly-Pro-Trp-Pro) ${ }^{+}, \quad 573.6$ $(651.7-\mathrm{CO})^{+}, 566.6(594.6-\mathrm{CO})^{+}, 557.6(585.6-\mathrm{CO})^{+}, 544.6$ (Pro-Trp-Pro-Tyr) ${ }^{+}, 516.6$ (488.5-CO) ${ }^{+}, 488.5$ (Phe-GlyPro-Trp)+ 465.5 (Tyr-Phe-Gly-Pro) ${ }^{+}, 460.5$ (488.5-CO) ${ }^{+}$,

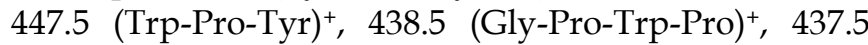
$(465.5-\mathrm{CO})^{+}, 419.5(447.5-\mathrm{CO})^{+}, 410.5(438.5-\mathrm{CO})^{+}, 381.4$ (Pro-Trp-Pro) $^{+}, 368.4$ (Tyr-Phe-Gly) ${ }^{+}, 341.4$ (Gly-ProTrp $)^{+}, 340.4$ (368.4-CO) ${ }^{+}, 313.4$ (341.4-CO) ${ }^{+}, 311.3$ (Tyr-

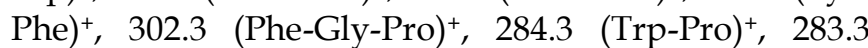
$(311.3-\mathrm{CO})^{+}, 256.3(284.3-\mathrm{CO})^{+}, 187.2(\mathrm{Trp})^{+}, 164.2$ $(\mathrm{Tyr})^{+}, 159.2\left(\mathrm{C}_{10} \mathrm{H}_{11} \mathrm{~N}_{2}\right)^{+}, 155.2{\text { (Gly-Pro })^{+},}^{+} 136.2$ $\left(\mathrm{C}_{8} \mathrm{H}_{10} \mathrm{NO}\right)^{+}, 130.1\left(\mathrm{C}_{9} \mathrm{H}_{8} \mathrm{~N}\right)^{+}, 127.2(155.2-\mathrm{CO})^{+}, 120.2$ $\left(\mathrm{C}_{8} \mathrm{H}_{10} \mathrm{~N}\right)^{+}, \quad 116.1 \quad\left(\mathrm{C}_{8} \mathrm{H}_{6} \mathrm{~N}\right)^{+}, \quad 107.1 \quad\left(\mathrm{C}_{7} \mathrm{H}_{7} \mathrm{O}\right)^{+}, \quad 93.1$ $\left(\mathrm{C}_{6} \mathrm{H}_{5} \mathrm{O}\right)^{+}, 91.1\left(\mathrm{C}_{7} \mathrm{H}_{7}\right)^{+}, 77.1\left(\mathrm{C}_{6} \mathrm{H}_{5}\right)^{+}, 70.1\left(\mathrm{C}_{4} \mathrm{H}_{8} \mathrm{~N}\right)^{+}, 58.0$ 
$(\mathrm{Gly})^{+}, 30.0\left(\mathrm{CH}_{4} \mathrm{~N}\right)^{+}$ppm; Anal. Calcd. for $\mathrm{C}_{41} \mathrm{H}_{45} \mathrm{~N}_{7} \mathrm{O}_{7}$ : C, 65.85; H, 6.06; N, 13.11. Found: C, 65.88; H, 6.05; N, $13.09 \%$.

\section{Diandrine C}

Pale yellow needles, m.p. $114-115^{\circ} \mathrm{C}$, yield $83.2 \%$ (NMM), 75.7\% (TEA), 68.9\% $\left(\mathrm{C}_{5} \mathrm{H}_{5} \mathrm{~N}\right),[\alpha]_{\mathrm{D}}:+2.1^{\circ}\left(+2.2^{\circ}\right)$ $(\mathrm{MeOH}, \mathrm{c} 0.19), \mathrm{R}_{\mathrm{f}}-0.84$. IR (KBr): $v 3476$ ( $m,-\mathrm{NH}$ str, indole ring), $3372(m,-\mathrm{OH}$ str, Tyr), 3127, 3125-3122 ( $m$, -NH str, amide), 3075, 3072 ( $w,-\mathrm{CH}$ str, aromatic rings), 2997, 2994-2989 ( $m$, -CH str, cyclic $\mathrm{CH}_{2}$ and $\left.\mathrm{CH}\right), 2928$, 2925-2922 ( $m,-\mathrm{CH}$ str, asym, $\left.\mathrm{CH}_{2}\right), 2848-2845,2842(m,-$ $\mathrm{CH}$ str, sym, $\left.\mathrm{CH}_{2}\right), 1674,1669,1635-1632\left(s,-\mathrm{C}=\mathrm{O}\right.$ str, $3^{\circ}$ and $2^{\circ}$ amide), 1555-1552, 1425-1421 ( $m$, skeletal bands, aromatic rings), 1539, 1535 ( $m$, $-\mathrm{NH}$ bend, $2^{\circ}$ amide), 721-717, 695- 689 (s, -CH bend, oop, aromatic rings) $\mathrm{cm}$ 1. ${ }^{1} \mathrm{H}$ NMR $\left(300 \mathrm{MHz}, \mathrm{CDCl}_{3}\right): \delta 9.85(1 \mathrm{H}, b r . s,-\mathrm{NH}$, Tyr), $9.16(1 \mathrm{H}, b r . s,-\mathrm{NH}$, Gly-2), $7.65(1 \mathrm{H}, b r . s,-\mathrm{NH}$, Trp), $7.42(2 \mathrm{H}, b r . s,-\mathrm{NH}$, indole ring and $-\mathrm{OH}, \mathrm{Tyr})$, 7.41-7.39 $(1 \mathrm{H}, d, \mathrm{~J}=7.8 \mathrm{~Hz}, \alpha-\mathrm{H}$, indole ring), 7.25-7.23 $(1 \mathrm{H}, d, \mathrm{~J}=7.25 \mathrm{~Hz}, \gamma-\mathrm{H}$, indole ring), 7.16-7.07 $(3 \mathrm{H}, m, \delta-$ $\zeta$ - $\mathrm{H}^{\prime} \mathrm{s}$, indole ring), 6.99-6.95 $(2 \mathrm{H}, d d, \mathrm{~J}=8.6,4.75 \mathrm{~Hz}, \mathrm{~m}-$ $\left.\mathrm{H}^{\prime} \mathrm{s}, \mathrm{Tyr}\right), 6.92-6.88\left(2 \mathrm{H}, d d, \mathrm{~J}=8.65,5.3 \mathrm{~Hz}, \mathrm{o}-\mathrm{H}^{\prime} \mathrm{s}, \mathrm{Tyr}\right)$, $6.26(1 \mathrm{H}, b r . s,-\mathrm{NH}, \mathrm{Gly}-1), 5.78-5.74(1 \mathrm{H}, q, \mathrm{~J}=6.15 \mathrm{~Hz}$, $\alpha-\mathrm{H}, \operatorname{Trp}), 5.31-5.29\left(2 \mathrm{H}, d, J=4.7 \mathrm{~Hz}, \mathrm{CH}_{2}, \mathrm{Gly}-2\right), 4.23-$ $4.19(1 \mathrm{H}, q, \mathrm{~J}=7.75 \mathrm{~Hz}, \alpha-\mathrm{H}, \mathrm{Tyr}), 3.96-3.94(2 \mathrm{H}, d, \mathrm{~J}=$ $\left.4.75 \mathrm{~Hz}, \mathrm{CH}_{2}, \mathrm{Gly}-1\right), 3.91-3.86\left(2 \mathrm{H}, m, \alpha-\mathrm{H}^{\prime}\right.$ s, Pro- 1 and Pro-2), 3.27-3.21 (4H, $m, \delta-\mathrm{H}^{\prime} \mathrm{s}$, Pro-1 and Pro-2), 2.90$2.88\left(2 \mathrm{H}, d, \mathrm{~J}=5.7 \mathrm{~Hz}, \beta-\mathrm{H}^{\prime} \mathrm{s}, \operatorname{Trp}\right), 2.69-2.63(4 \mathrm{H}, m, \beta-$ H's, Pro-1 and Pro-2), 2.61-2.59 $(2 \mathrm{H}, d, J=5.65 \mathrm{~Hz}, \beta-$ $\left.\mathrm{H}^{\prime} \mathrm{s}, \mathrm{Tyr}\right), 1.88-1.79\left(4 \mathrm{H}, m, \gamma-\mathrm{H}^{\prime} \mathrm{s}\right.$, Pro-1 and Pro-2) ppm. ${ }^{13} \mathrm{C}$ NMR $\left(\mathrm{CDCl}_{3}, 300 \mathrm{MHz}\right): \delta$ 173.2, 172.9 (2C, $\mathrm{C}=\mathrm{O}$, Tyr and Pro-2), 171.2, 169.9 (2C, C=O, Pro-1 and Trp), 164.8, $163.2(2 \mathrm{C}, \mathrm{C}=\mathrm{O}, \mathrm{Gly}-2$ and Gly-1), $154.0(\mathrm{p}-\mathrm{C}$, Tyr), $136.7\left(\alpha^{\prime}-\mathrm{C}\right.$, indole ring), $133.9(\gamma-\mathrm{C}, \mathrm{Tyr}), 130.2$ (2C, o-C's, Tyr), 128.7 (2C, m-C's, Tyr), 126.7 ( $\beta^{\prime}-\mathrm{C}$, indole ring), $125.5,125.9$ (2C, $\alpha-C$ and $\varepsilon-C$, indole ring), $120.4,118.9$ (2C, $\delta$-C and $\gamma-C$, indole ring), 111.8, 110.3 (2C, $\beta-C$ and $\zeta-C$, indole ring), 65.4 ( $\alpha-C$, Pro- 2$), 58.0(\alpha-$ C, Pro-1), $57.5(\alpha-\mathrm{C}, \mathrm{Trp}), 52.8\left(\alpha-\mathrm{C}\right.$, Tyr), $49.7\left(\mathrm{CH}_{2}\right.$, Gly-1), 49.1, 47.0 (2C, $\delta$-C's, Pro-2 and Pro-1), $42.4\left(\mathrm{CH}_{2}\right.$, Gly-2), 37.7 ( $\beta-C, \mathrm{Tyr}), 33.3$ ( $\beta-\mathrm{C}$, Pro-1), 31.5 ( $\beta-\mathrm{C}$, Pro2), 26.7 ( $\beta$-C, Trp), 25.0, 23.3 (2C, $\gamma$-C's, Pro-2 and Pro-1) ppm. FAB MS: $m / z 658.7(\mathrm{M}+\mathrm{H})^{+}, 630.7(658.7-\mathrm{CO})^{+}$, 601.6 (Gly-Pro-Tyr-Trp-Pro) ${ }^{+}, 573.6$ (601.6-CO)+ ${ }^{+}, 561.6$ (Tyr-Trp-Pro-Gly-Gly) ${ }^{+}, 533.6$ (561.6-CO)+ 504.5 (TyrTrp-Pro-Gly) ${ }^{+}, 476.5$ (504.5-CO) ${ }^{+}, 472.5$ (Pro-Gly-GlyPro-Tyr) ${ }^{+}, 447.5$ (Tyr-Trp-Pro) ${ }^{+}, 444.5$ (472.5-CO) ${ }^{+}, 419.5$ (447.5-CO)+ , 375.4 (Gly-Gly-Pro-Tyr) ${ }^{+}, 350.4$ (Tyr-Trp) ${ }^{+}$, 347.4 (375.4-CO)+, 322.4 (350.4-CO)+ 318.3 (Gly-Pro$\mathrm{Tyr}^{+}, 309.3$ (Pro-Gly-Gly-Pro) ${ }^{+}, 290.3$ (318.3-CO) ${ }^{+}, 281.3$ $(309.3-\mathrm{CO})^{+}, 212.2$ (Pro-Gly-Gly) $^{+}, 184.2(212.2-\mathrm{CO})^{+}$, $164.2(\mathrm{Tyr})^{+}, 159.2\left(\mathrm{C}_{10} \mathrm{H}_{11} \mathrm{~N}_{2}\right)^{+}, 155.2$ (Pro-Gly) ${ }^{+}, 136.2$ $\left(\mathrm{C}_{8} \mathrm{H}_{10} \mathrm{NO}\right)^{+}, 130.1\left(\mathrm{C}_{9} \mathrm{H}_{8} \mathrm{~N}\right)^{+}, 127.2(155.2-\mathrm{CO})^{+}, 116.1$ $\left(\mathrm{C}_{8} \mathrm{H}_{6} \mathrm{~N}\right)^{+}, 115.1$ (Gly-Gly) ${ }^{+}, 107.1\left(\mathrm{C}_{7} \mathrm{H}_{7} \mathrm{O}\right)^{+}, 98.1$ (Pro) ${ }^{+}$, $93.1\left(\mathrm{C}_{6} \mathrm{H}_{5} \mathrm{O}\right)^{+}, 70.1\left(\mathrm{C}_{4} \mathrm{H}_{8} \mathrm{~N}\right)^{+}, 30.0\left(\mathrm{CH}_{4} \mathrm{~N}\right)^{+}$ppm.

\section{Fanlizhicyclopeptide A}

Pale yellow solid; m.p. $137-139^{\circ} \mathrm{C}$ (d); Yield $85 \%$ $\left(\mathrm{C}_{5} \mathrm{H}_{5} \mathrm{~N}\right), 78 \%(\mathrm{NMM}), 68 \%(\mathrm{TEA}) ;[\alpha]_{\mathrm{D}}=-74.2^{\circ}(c=$
$0.54, \mathrm{MeOH})\left(-74.1^{\circ}\right.$ for natural fanlizhicyclopeptide A [11]); $\mathrm{R}_{f}=0.77\left(\mathrm{CHCl}_{3} \cdot \mathrm{MeOH}-9: 1\right) ; \mathrm{IR}(\mathrm{KBr}): v=3372$ $\left(\mathrm{O}-\mathrm{H}_{\text {str, }}\right.$ aromatic ring $), 3128-3125,3123-3119\left(\mathrm{~N}-\mathrm{H}_{\text {str, }}\right.$, amide), 3067-3061 ( $\mathrm{Ar}-\mathrm{H}_{\text {str }}$, aromatic ring), 2999, 29962991 (C-H $\mathrm{H}_{\text {str }}$, cyclic $\left.\mathrm{CH}_{2}\right), 2967,2925-2919$ (C-H $\mathrm{H}_{\text {str }}$, asym, $\mathrm{CH}_{3}$ and $\left.\mathrm{CH}_{2}\right), 2853,2949-2843\left(\mathrm{C}-\mathrm{H}_{\text {str }}, \mathrm{sym}, \mathrm{CH}_{2}\right)$, $1668-1664,1642,1639\left(\mathrm{C}=\mathrm{O}_{\text {str }}, 3^{\circ}\right.$ and $2^{\circ}$ amide $), 1566$, 1439 (skeletal bands), 1538, 1532-1529 (N-H $\mathrm{H}_{\text {def, }} 2^{\circ}$ amide), 1380, 1362 (C-H $\mathrm{H}_{\text {def, }}$ iso-propyl), 716, 687 $\left(\mathrm{C}-\mathrm{H}_{\text {def, }}\right.$ oop, aromatic ring) $\mathrm{cm}^{-1} ;{ }^{1} \mathrm{H}$ NMR $\left(\mathrm{CDCl}_{3}\right): \delta=$ 9.88 (br. s, 1 H, NH, Tyr), 9.69 (br. s, 1 H, NH, Leu), 9.18 (br. s, 1 H, NH, Gly), 7.85 (br. s, 1 H, NH, Val), 6.99, 6.95 $\left(\mathrm{dd}, J=8.6,5.25 \mathrm{~Hz}, 2 \mathrm{H}, m-\mathrm{H}^{\prime} \mathrm{s}, \mathrm{Tyr}\right), 6.89,6.86(\mathrm{dd}, J=$ $\left.8.55,4.9 \mathrm{~Hz}, 2 \mathrm{H}, o-\mathrm{H}^{\prime} \mathrm{s}, \mathrm{Tyr}\right), 6.55(\mathrm{t}, J=5.9 \mathrm{~Hz}, 1 \mathrm{H}, \alpha-$ $\mathrm{H}, \mathrm{Val}), 6.33-6.28(\mathrm{~m}, J=6.7 \mathrm{~Hz}, 1 \mathrm{H}, \alpha-\mathrm{H}, \mathrm{Leu}), 5.97$ (br. $\mathrm{s}, 1 \mathrm{H}, \mathrm{OH}, \mathrm{Tyr}), 4.25(\mathrm{t}, 1 \mathrm{H}, J=6.85 \mathrm{~Hz}, \alpha-\mathrm{H}$, Pro-2), 4.21-4.37 (q, J = 7.85 Hz, $1 \mathrm{H}, \alpha-\mathrm{H}, \mathrm{Tyr}), 4.02(\mathrm{~d}, J=5.45$ $\mathrm{Hz}, 2 \mathrm{H}, \alpha-\mathrm{H}^{\prime} \mathrm{s}$, Gly), 3.89 (t, $1 \mathrm{H}, J=6.9 \mathrm{~Hz}, \alpha-\mathrm{H}$, Pro-3), $3.75(\mathrm{t}, J=6.85 \mathrm{~Hz}, 1 \mathrm{H}, \alpha-\mathrm{H}$, Pro-1), $3.51(\mathrm{t}, 2 \mathrm{H}, J=7.2$ $\mathrm{Hz}, \delta-\mathrm{H}$, Pro-2), $3.23(\mathrm{t}, J=7.15 \mathrm{~Hz}, 2 \mathrm{H}, \delta-\mathrm{H}$, Pro-3), $2.95(\mathrm{t}, J=7.2 \mathrm{~Hz}, 2 \mathrm{H}, \delta-\mathrm{H}$, Pro-1), 2.71-2.65 (m, $4 \mathrm{H}, \beta-$ H's, Pro-1 and Pro-3), 2.64-2.60 (m, $2 \mathrm{H}, \beta$-H's, Pro-2), $2.57\left(\mathrm{~d}, J=5.45 \mathrm{~Hz}, 2 \mathrm{H}, \beta-\mathrm{H}^{\prime} \mathrm{s}, \mathrm{Tyr}\right), 1.89(\mathrm{t}, 2 \mathrm{H}, J=5.85$ $\mathrm{Hz}, \beta$-H's, Leu), 1.87-1.78 (m, $6 \mathrm{H}, \gamma-\mathrm{H}^{\prime} \mathrm{s}$, Pro-2, Pro-3 and Pro-1), 1.67-1.62 (m, $1 \mathrm{H}, \beta-\mathrm{H}, \mathrm{Val}), 1.15(\mathrm{~d}, 6 \mathrm{H}, \mathrm{J}=$ $\left.4.55 \mathrm{~Hz}, \gamma-\mathrm{H}^{\prime} \mathrm{s}, \mathrm{Val}\right), 0.99(\mathrm{~d}, 6 \mathrm{H}, J=6.25 \mathrm{~Hz}, \delta$-H's, Leu), 0.86-0.79 (m, $1 \mathrm{H}, \gamma-\mathrm{H}$, Leu); ${ }^{13} \mathrm{C}$ NMR $\left(\mathrm{CDCl}_{3}\right): \delta=$ $173.9(\mathrm{C}=\mathrm{O}$, Leu $), 172.0,171.3(2 \mathrm{C}, \mathrm{C}=\mathrm{O}$, Pro-3 and Tyr), 170.8, 170.3, (2 C, C=O, Pro-2 and Val), 169.7, 169.1 (2 C, C=O, Pro-1 and Gly), 153.8 ( $p$-C, Tyr), $135.6(\gamma-\mathrm{C}$, Tyr), 131.3 (2 C, m-C's, Tyr), 129.1 (2 C, o-C's, Tyr), 62.2, 58.4, 56.1 (3 C, $a-C^{\prime}$ s, Pro-3, Pro-2 and Pro-1), 55.8 ( $a-C$, Val), 54.9, 54.5 (2 C, $a-C^{\prime}$ s, Leu and Tyr), 49.3, 46.5, 45.1 (3 C, $\delta$-C's, Pro-3, Pro-2 and Pro-1), 43.6, 42.0 (2 C, $\beta$ C's, Leu and Tyr), 40.9 (a-C, Gly), 34.6, 33.7, 30.1 (3 C, $\beta$ C's, Pro-3, Pro-1 and Pro-2), 29.9 ( $\beta$-C, Val), $29.0(\gamma-\mathrm{C}$, Leu), 24.1, 23.8 (2 C, $\gamma$-C's, Pro-3 and Pro-1), 23.1 (2 C, $\delta$ C's, Leu), $20.7(\gamma-\mathrm{C}$, Pro-2), 18.9 (2 C, $\gamma$-C's, Val); MS $(\mathrm{FAB}, 70 \mathrm{eV}): \mathrm{m} / \mathrm{z}(\%)=724(100)[\mathrm{M}+1]^{+}, 696$ (11) [724$\mathrm{CO}{ }^{+}, 667$ (39) [Val-Pro-Pro-Tyr-Leu-Pro] ${ }^{+}, 639$ (17) [667-CO] ${ }^{+}, 627$ (78) [Pro-Tyr-Leu-Pro-Gly-Val] ${ }^{+}, 625$ (49) [Pro-Pro-Tyr-Leu-Pro-Gly] ${ }^{+}, 611$ (64) [Pro-Gly-Val-ProPro-Tyr $]^{+}, 599$ (19) [627-CO ${ }^{+}, 597$ (16) [625-CO ${ }^{+}, 583$ (16) [611-CO] ${ }^{+}, 570$ (48) [Val-Pro-Pro-Tyr-Leu] ${ }^{+}, 568$ (37) [Pro-Pro-Tyr-Leu-Pro] ${ }^{+}, 542$ (11) [570-CO] ${ }^{+}, 540$ (13) $[568-\mathrm{CO}]^{+}, 530$ (76) [Tyr-Leu-Pro-Gly-Val] ${ }^{+}, 528$ (41) [Pro-Tyr-Leu-Pro-Gly] ${ }^{+}, 502$ (11) [530-CO] ${ }^{+}, 500$ (15) $[528-\mathrm{CO}]^{+}, 471$ (76) [Pro-Pro-Tyr-Leu] ${ }^{+}, 457$ (23) [ValPro-Pro-Tyr] ${ }^{+}, 448$ (52) [Pro-Gly-Val-Pro-Pro] ${ }^{+}, 443$ (29) $[471-\mathrm{CO}]^{+}, 431$ (23) [Tyr-Leu-Pro-Gly] ${ }^{+}, 429$ (16) [457$\mathrm{CO}^{+}, 420$ (11) [448-CO ${ }^{+}, 403$ (14) [431-CO ${ }^{+}, 374$ (48) [Pro-Tyr-Leu] $]^{+}, 358$ (61) [Pro-Pro-Tyr] ${ }^{+}, 351$ (72) [ProGly-Val-Pro] ${ }^{+}, 346$ (17) [374-CO ${ }^{+}, 330$ (14) [358-CO] ${ }^{+}$, 323 (16) [351-CO] ${ }^{+}, 294$ (38) [Val-Pro-Pro] ${ }^{+}, 277$ (41) [Tyr-Leu] ${ }^{+}, 261$ (33) [Pro-Tyr] ${ }^{+}, 254$ (33) [Pro-Gly-Val] ${ }^{+}$, 233 (10) [261-CO]+ 226 (14) [254-CO] ${ }^{+}, 195$ (27) [Pro$\mathrm{Pro}^{+}, 167$ (11) [195-CO] ${ }^{+}, 155$ (29) [Pro-Gly] ${ }^{+}, 136$ (19) [Tyr immonium ion, $\left.\mathrm{C}_{8} \mathrm{H}_{10} \mathrm{NO}\right]^{+}, 127$ (21) [155-CO] ${ }^{+}, 107$ Int. J. Pharm. Sci. Drug Res. November-December, 2018, Vol 10, Issue 6 (480-486) 
(10) $\left[\mathrm{C}_{7} \mathrm{H}_{7} \mathrm{O}\right]^{+}, 98(22)[\mathrm{Pro}]^{+}, 93(13)\left[\mathrm{C}_{6} \mathrm{H}_{5} \mathrm{O}\right]^{+}, 86(21)$ [Leu immonium ion, $\left.\mathrm{C}_{5} \mathrm{H}_{12} \mathrm{~N}\right]^{+}, 72(26)$ [Val immonium ion, $\left.\mathrm{C}_{4} \mathrm{H}_{10} \mathrm{~N}\right]^{+}, 70$ (34) [Pro immonium ion, $\left.\mathrm{C}_{4} \mathrm{H}_{8} \mathrm{~N}\right]^{+}, 57$ (14) $\left[\mathrm{C}_{4} \mathrm{H}_{9}\right]^{+}, 43(28)\left[\mathrm{C}_{3} \mathrm{H}_{7}\right]^{+}, 30(16)$ [Gly immonium ion, $\left.\mathrm{CH}_{4} \mathrm{~N}\right]^{+}, 17(10)[\mathrm{OH}]^{+}, 15(21)\left[\mathrm{CH}_{3}\right]^{+} ; \mathrm{C}_{37} \mathrm{H}_{53} \mathrm{~N}_{7} \mathrm{O}_{8}$ (723): calcd. C 61.39, H 7.38, N 13.54; found C 61.41, H 7.36, N 13.55 .

\section{Fanlizhicyclopeptide B}

Pale yellow solid; m.p. $121-123^{\circ} \mathrm{C}$ (d); Yield $87 \%$ $\left(\mathrm{C}_{5} \mathrm{H}_{5} \mathrm{~N}\right), 79 \%(\mathrm{NMM}), 73 \%(\mathrm{TEA}) ;[\alpha]_{\mathrm{D}}=-113.5^{\circ}(c=$ $0.41, \mathrm{MeOH})\left(-113.6^{\circ}\right.$ for natural fanlizhicyclopeptide B [14]); $\mathrm{R}_{f}=0.68\left(\mathrm{CHCl}_{3} \cdot \mathrm{MeOH}-9: 1\right) ; \mathrm{IR}(\mathrm{KBr}): v=3375$ $\left(\mathrm{O}-\mathrm{H}_{\text {str, }}\right.$ aromatic ring), 3128-3124, $3121 \quad\left(\mathrm{~N}-\mathrm{H}_{\text {str, }}\right.$ amide), 3068-3063 (Ar- $\mathrm{H}_{\text {str, }}$ aromatic ring), 2998-2992 $\left(\mathrm{C}-\mathrm{H}_{\text {str, }}\right.$ cyclic $\left.\mathrm{CH}_{2}\right), 2969,2925,2918\left(\mathrm{C}-\mathrm{H}_{\text {str }}\right.$, asym, $\mathrm{CH}_{3}$

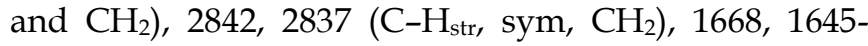
$1639\left(\mathrm{C}=\mathrm{O}_{\text {str }}, 3^{\circ}\right.$ and $2^{\circ}$ amide), 1567, 1435 (skeletal bands), 1535, 1531-1527 (N-H def, amide), 714, 685

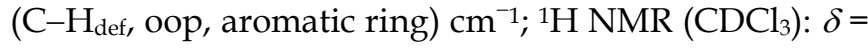
8.68 (br. s, 1 H, NH, Ile), 8.35 (br. s, 1 H, NH, Tyr), 7.72 (br. s, $1 \mathrm{H}, \mathrm{NH}, \mathrm{Ala}$ ), 7.25 (br. s, $1 \mathrm{H}, \mathrm{NH}, \mathrm{Gly}), 6.99,6.96$ (dd, J = 8.6, $\left.4.9 \mathrm{~Hz}, 2 \mathrm{H}, o-\mathrm{H}^{\prime} \mathrm{s}, \mathrm{Tyr}\right), 6.88,6.85$ (dd, $J=$

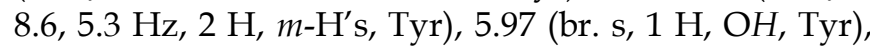
5.94-5.89 (m, $1 \mathrm{H}, \alpha-\mathrm{H}, \mathrm{Ala}), 5.68-5.64(\mathrm{q}, J=7.85 \mathrm{~Hz}, 1$ $\mathrm{H}, \alpha-\mathrm{H}, \mathrm{Tyr}), 5.29$ (d, J = 5.5 Hz, $\left.2 \mathrm{H}, \alpha-\mathrm{H}^{\prime} \mathrm{s}, \mathrm{Gly}\right), 3.89(\mathrm{t}$, $1 \mathrm{H}, J=6.9 \mathrm{~Hz}, \alpha-\mathrm{H}$, Pro), $3.81(\mathrm{t}, J=8.6 \mathrm{~Hz}, 1 \mathrm{H}, \alpha-\mathrm{H}$, Ile), 3.25 (t, $2 \mathrm{H}, J=7.15 \mathrm{~Hz}, \delta-\mathrm{H}$, Pro), 2.68-2.64 (m, $2 \mathrm{H}$, $\beta$-H's, Pro), 2.37 (d, J = $5.5 \mathrm{~Hz}, 2 \mathrm{H}, \beta$-H's, Tyr), $1.85-$ 1.79 (m, $2 \mathrm{H}, \gamma-\mathrm{H}^{\prime} \mathrm{s}$, Pro), 1.63-1.58 (m, $\left.2 \mathrm{H}, \gamma-\mathrm{H}^{\prime} \mathrm{s}, \mathrm{Ile}\right)$, 1.53-1.48 (m, $1 \mathrm{H}, \beta$-H's, Ile), 1.44 (d, $3 \mathrm{H}, J=5.85 \mathrm{~Hz}, \beta$ H's, Ala), 1.01 (d, J = 5.9 Hz, $\left.3 \mathrm{H}, \gamma^{\prime}-\mathrm{H}^{\prime} \mathrm{s}, \mathrm{Ile}\right), 0.96$ (t, $3 \mathrm{H}$, $J=7.8 \mathrm{~Hz}, \delta$-H's, Ile); ${ }^{13} \mathrm{C} \mathrm{NMR}\left(\mathrm{CDCl}_{3}\right): \delta=173.3(\mathrm{C}=\mathrm{O}$, Ala), 172.1 ( $\mathrm{C}=\mathrm{O}, \mathrm{Tyr}), 170.7(\mathrm{C}=\mathrm{O}$, Ile), $170.2(\mathrm{C}=\mathrm{O}$, Pro), 163.5 (C=O, Gly), 152.6 ( $p-\mathrm{C}, \mathrm{Tyr}), 133.7$ ( $\gamma$-C, Tyr), 129.2 (2 C, o-C's, Tyr), 127.9 (2 C, m-C's, Tyr), 59.0, 56.2, 53.7 (3 C, a-C's, Ile, Pro and Tyr), 49.2, 48.7 (2 C, a-C's, Gly and Ala), 48.0 ( $\delta$-C, Pro), 39.9, 36.4, 32.7 (3 C, $\beta$-C's, Tyr, Ile and Pro), 24.4, 22.8 (2 C, $\gamma$-C's, Ile and Pro), 17.8 $\left(\beta\right.$-C, Ala), 16.9 ( $\gamma^{\prime}-\mathrm{C}$, Ile), 10.6 ( $\delta$-C, Ile); MS (FAB, 70 $\mathrm{eV}): m / z(\%)=502(100)[\mathrm{M}+1]^{+}, 474(14)[502-\mathrm{CO}]^{+}, 431$ (64) [Gly-Pro-Ile-Tyr] ${ }^{+}, 403$ (15) [431-CO]+ 389 (38) Table 1: Cytotoxic activity data of Diandrine A

\begin{tabular}{|c|c|c|c|c|c|c|c|c|c|}
\hline \multirow[b]{2}{*}{ Compd. } & \multirow[b]{2}{*}{$\begin{array}{l}\text { Conc. } \\
(\mu \mathrm{g} / \mathrm{ml})\end{array}$} & \multicolumn{4}{|c|}{ HCT116 } & \multicolumn{4}{|c|}{ B16F10 } \\
\hline & & $\begin{array}{c}\text { Live cells } \\
\text { counted }\end{array}$ & $\begin{array}{c}\text { No. of } \\
\text { dead cells }\end{array}$ & $\begin{array}{l}\% \text { growth } \\
\text { inhibition }^{\text {a }}\end{array}$ & $\begin{array}{c}\mathrm{b}^{\mathrm{b}} \mathrm{CTC}_{50} \\
(\mu \mathrm{M})\end{array}$ & $\begin{array}{c}\text { Live cells } \\
\text { counted }\end{array}$ & $\begin{array}{c}\text { No. of dead } \\
\text { cells }\end{array}$ & $\begin{array}{l}\% \text { growth } \\
\text { inhibition }^{a}\end{array}$ & $\begin{array}{c}{ }^{\mathrm{b}} \mathrm{CTC}_{50} \\
(\mu \mathrm{M})\end{array}$ \\
\hline \multirow{5}{*}{ Diandrine A } & 120 & $04 \pm 1.21$ & $36 \pm 1.29$ & $90 \pm 1.35$ & \multirow{5}{*}{20.16} & $05 \pm 1.69$ & $35 \pm 1.15$ & $87.5 \pm 2.08$ & \multirow{5}{*}{20.91} \\
\hline & 60 & $08 \pm 1.30$ & $32 \pm 2.01$ & $80 \pm 2.03$ & & $10 \pm 2.14$ & $30 \pm 1.35$ & $75 \pm 1.97$ & \\
\hline & 30 & $14 \pm 1.14$ & $26 \pm 2.38$ & $65 \pm 2.14$ & & $15 \pm 2.31$ & $25 \pm 1.02$ & $62.5 \pm 1.69$ & \\
\hline & 15 & $22 \pm 1.59$ & $18 \pm 1.98$ & $45 \pm 1.88$ & & $23 \pm 1.05$ & $17 \pm 02.11$ & $42.5 \pm 1.33$ & \\
\hline & 7.5 & $29 \pm 1.87$ & $11 \pm 2.34$ & $27.5 \pm 2.31$ & & $30 \pm 1.08$ & $10 \pm 2.06$ & $25 \pm 2.04$ & \\
\hline \multirow{5}{*}{ Control } & 120 & 40 & 0 & 0 & \multirow{5}{*}{0} & 40 & 0 & 0 & \multirow{5}{*}{0} \\
\hline & 60 & 40 & 0 & 0 & & 40 & 0 & 0 & \\
\hline & 30 & 40 & 0 & 0 & & 40 & 0 & 0 & \\
\hline & 15 & 40 & 0 & 0 & & 40 & 0 & 0 & \\
\hline & 7.5 & 40 & 0 & 0 & & 40 & 0 & 0 & \\
\hline \multirow{5}{*}{ Doxorubicin } & 120 & 0 & $40 \pm 1.01$ & $100 \pm 1.01$ & \multirow{5}{*}{7.05} & 0 & $40 \pm 1.01$ & $100 \pm 1.04$ & \multirow{5}{*}{6.51} \\
\hline & 60 & 0 & $40 \pm 1.01$ & $100 \pm 1.02$ & & 0 & $40 \pm 1.01$ & $100 \pm 1.03$ & \\
\hline & 30 & $08 \pm 1.17$ & $32 \pm 1.21$ & $80 \pm 1.19$ & & $10 \pm 1.11$ & $30 \pm 1.17$ & $75 \pm 1.21$ & \\
\hline & 15 & $16 \pm 1.13$ & $24 \pm 1.14$ & $60 \pm 1.17$ & & $17 \pm 1.16$ & $23 \pm 1.19$ & $57.5 \pm 1.24$ & \\
\hline & 7.5 & $22 \pm 1.15$ & $18 \pm 1.27$ & $45 \pm 1.14$ & & $24 \pm 1.12$ & $16 \pm 1.18$ & $40 \pm 1.15$ & \\
\hline
\end{tabular}

\footnotetext{
a $\%$ growth inhibition $=100-\left[\{(\right.$ Celltotal - Celldead $) \times 100\} /$ Cell $\left.l_{\text {total }}\right] ;{ }^{b} C^{2} C_{50}=$ conc. inhibiting $50 \%$ of percentage growth $(\mathrm{n}=3)$
}

[Tyr-Ala-Gly-Pro] ${ }^{+}, 377$ (11) [405-CO]+ 374 (76) [Pro-IleTyr $]^{+}, 361$ (18) [389-CO ${ }^{+}, 348$ (59) [Ile-Tyr-Ala $]^{+}, 346$ (15) [374-CO]+ 339 (49) [Ala-Gly-Pro-Ile] ${ }^{+}, 320$ (16) [348$\mathrm{CO}^{+}, 311$ (14) [339-CO]+, 292 (61) [Tyr-Ala-Gly] ${ }^{+}, 277$ (28) [Ile-Tyr] ${ }^{+}, 268$ (46) [Gly-Pro-Ile] ${ }^{+}, 240$ (13) [268$\mathrm{CO}^{+}, 235$ (45) [Tyr-Ala] ${ }^{+}, 211$ (39) [Pro-Ile] ${ }^{+}, 207$ (11) $\left[235-\mathrm{CO}^{+}, 198(10)[226-\mathrm{CO}]^{+}, 183(10)\left[211-\mathrm{CO}^{+}, 155\right.\right.$

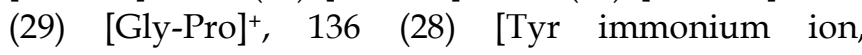
$\left.\mathrm{C}_{8} \mathrm{H}_{10} \mathrm{NO}\right]^{+}, 129$ (19) [Ala-Gly] ${ }^{+}, 127$ (10) [155-CO] ${ }^{+}, 107$ $\left[\mathrm{C}_{7} \mathrm{H}_{7} \mathrm{O}\right]^{+}, 93(13)\left[\mathrm{C}_{6} \mathrm{H}_{5} \mathrm{O}\right]^{+}, 86$ (21) [Ile immonium ${ }_{2} \mathrm{~N}^{+}, 70$ (38) [Pro immonium ion, $\mathrm{C}_{4} \mathrm{H}_{8} \mathrm{~N}{ }^{+}, 57$ $\left.\mathrm{C}_{4} \mathrm{H}_{9}\right]^{+}, 44$ (18) [Ala immonium ion, $\left.\mathrm{C}_{2} \mathrm{H}_{6} \mathrm{~N}\right]^{+}, 30$ Gly immonium ion, $\left.\mathrm{CH}_{4} \mathrm{~N}\right]^{+}, 29(12)\left[\mathrm{C}_{2} \mathrm{H}_{5}\right]^{+}, 17$ (11) $[\mathrm{OH}]^{+}, 15$ (24) $\left[\mathrm{CH}_{3}\right]^{+} ; \mathrm{C}_{25} \mathrm{H}_{35} \mathrm{~N}_{5} \mathrm{O}_{6}$ (501): calcd. C 59.87, H 7.03, N 13.96; found C 59.88, H 7.05, N 13.95.

\section{Evaluation of Cytotoxic Activity}

Synthesized cyclopeptides were subjected to short term in vitro cytotoxic study (from Deshpande Laboratories Pvt. Ltd., Bhopal) at 120-7.5 $\mu \mathrm{g} / \mathrm{ml}$ using Doxorubicin as reference compound. Activity was assessed by determining the percentage inhibition of HCT116 and B16F10 Cellline. Standard MTT assay was used to evaluate cell line viability in the presence of extracts. In 96 well plate, $100 \mu 1$ medium (RPMI 1640) was poured in each well and selected with 5000-10,000 HCT116 and B16F10 cells. Cells were allowed to attach overnight and then various concentration of the crude extract were added to respective wells. After $24 \mathrm{~h}$ incubation at $37^{\circ} \mathrm{C}, 5 \% \mathrm{CO} 2$ and relative humidity $20 \mu \mathrm{l}$ of MTT (5 $\mathrm{mg} / \mathrm{ml}$ ) was added to each cell. After further $4 \mathrm{~h}$ incubation at $37^{\circ} \mathrm{C}, 100 \mu \mathrm{l}$ of DMSO solutions was added to each well to solublize MTT crystals. The plates were again incubated overnight at conditions mentioned above. The plates were read for optical density at $570 \mathrm{~nm}$ as test wave length and $630 \mathrm{~nm}$ as the erence using using a plate reader. Percentage inhibition was calculated by following formula.

Control-Test Sample $\times 100$

Control 


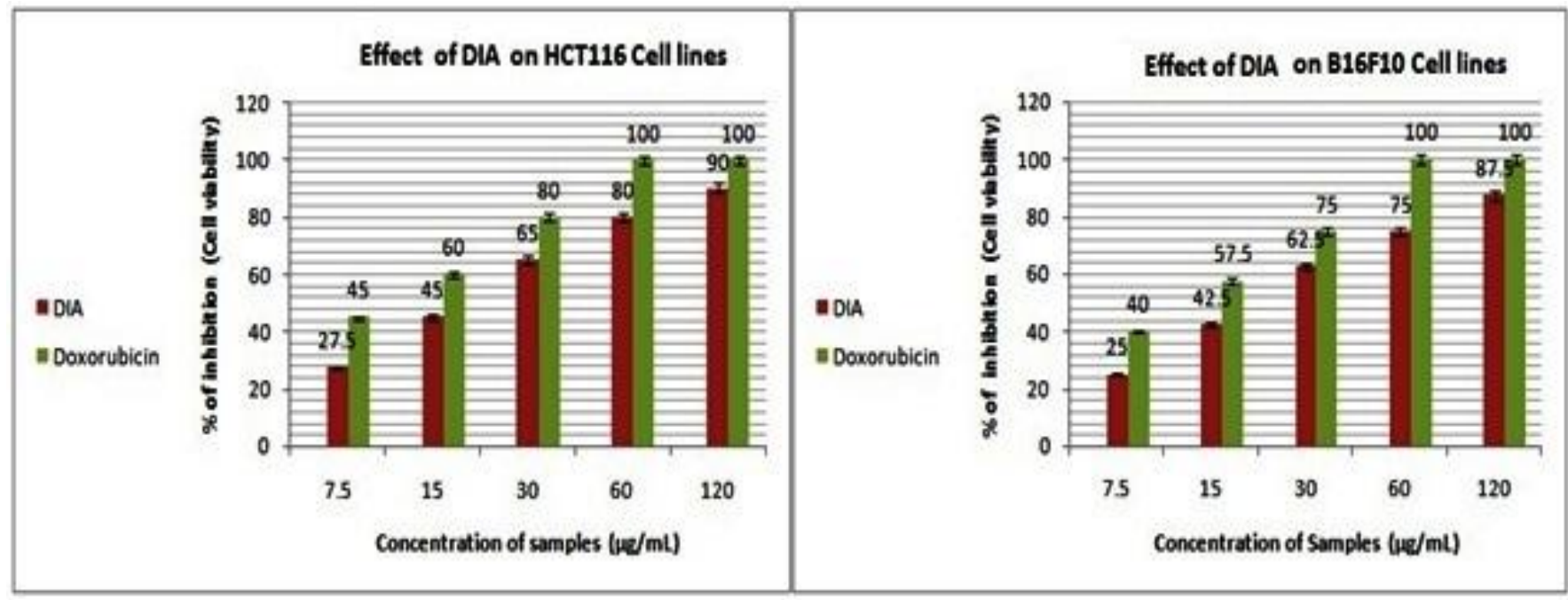

Fig. 1: Cytotoxic activity of Diandrine A

Table 2: Cytotoxic activity data of Diandrine C

\begin{tabular}{|c|c|c|c|c|c|c|c|c|c|}
\hline \multirow[b]{2}{*}{ Compd. } & \multirow[b]{2}{*}{$\begin{array}{l}\text { Conc. } \\
(\mu \mathrm{g} / \mathrm{ml})\end{array}$} & \multicolumn{4}{|c|}{ HCT116 } & \multicolumn{4}{|c|}{ B16F10 } \\
\hline & & $\begin{array}{l}\text { Live cells } \\
\text { counted }\end{array}$ & $\begin{array}{c}\text { No. of dead } \\
\text { cells }\end{array}$ & $\begin{array}{l}\text { \% growth } \\
\text { inhibition }^{\text {a }}\end{array}$ & $\begin{array}{c}{ }^{{ }^{b} C T C_{50}} \\
(\mu M)\end{array}$ & $\begin{array}{l}\text { Live cells } \\
\text { counted }\end{array}$ & $\begin{array}{c}\text { No. of dead } \\
\text { cells }\end{array}$ & $\begin{array}{l}\text { \% growth } \\
\text { inhibition }\end{array}$ & $\begin{array}{c}{ }^{\mathrm{b}^{2} \mathrm{CTC}} \mathrm{C}_{50} \\
(\boldsymbol{\mu} \mathrm{M})\end{array}$ \\
\hline \multirow{5}{*}{ Diandrine C } & 120 & $06 \pm 2.13$ & $34 \pm 2.19$ & $85 \pm 2.16$ & \multirow{5}{*}{16.42} & $08 \pm 2.15$ & $32 \pm 2.23$ & $80 \pm 2.87$ & \multirow{5}{*}{17.73} \\
\hline & 60 & $11 \pm 2.25$ & $29 \pm 2.21$ & $72.5 \pm 2.18$ & & $12 \pm 02.24$ & $28 \pm 2.19$ & $70 \pm 2.21$ & \\
\hline & 30 & $16 \pm 2.27$ & $24 \pm 2.24$ & $60 \pm 3.21$ & & $17 \pm 3.22$ & $23 \pm 2.26$ & $57.5 \pm 2.23$ & \\
\hline & 15 & $23 \pm 1.98$ & $17 \pm 2.22$ & $42.5 \pm 2.24$ & & $25 \pm 3.23$ & $15 \pm 2.24$ & $37.5 \pm 2.17$ & \\
\hline & 7.5 & $31 \pm 1.94$ & $9 \pm 2.25$ & $22.5 \pm 3.28$ & & $2 \pm 2.21$ & $08 \pm 2.27$ & $20 \pm 2.19$ & \\
\hline \multirow{5}{*}{ Control } & 120 & 40 & 0 & 0 & \multirow{5}{*}{0} & 40 & 0 & 0 & \multirow{5}{*}{0} \\
\hline & 60 & 40 & 0 & 0 & & 40 & 0 & 0 & \\
\hline & 30 & 40 & 0 & 0 & & 40 & 0 & 0 & \\
\hline & 15 & 40 & 0 & 0 & & 40 & 0 & 0 & \\
\hline & 7.5 & 40 & 0 & 0 & & 40 & 0 & 0 & \\
\hline \multirow{5}{*}{ Doxorubicin } & 120 & 0 & $40 \pm 1.12$ & $100 \pm 1.14$ & \multirow{5}{*}{5.973} & 0 & $40 \pm 1.19$ & $100 \pm 1.14$ & \multirow{5}{*}{6.51} \\
\hline & 60 & 0 & $40 \pm 1.11$ & $100 \pm 1.20$ & & 0 & $40 \pm 1.13$ & $100 \pm 1.14$ & \\
\hline & 30 & $17 \pm 1.14$ & $33 \pm 1.22$ & $82.5 \pm 1.19$ & & $18 \pm 1.11$ & $32 \pm 1.14$ & $80 \pm 1.12$ & \\
\hline & 15 & $12 \pm 1.15$ & $28 \pm 1.19$ & $70 \pm 1.24$ & & $14 \pm 1.16$ & $26 \pm 1.21$ & $65 \pm 1.21$ & \\
\hline & 7.5 & $22 \pm 1.11$ & $18 \pm 1.26$ & $45 \pm 1.21$ & & $23 \pm 1.12$ & $17 \pm 1.18$ & $42.5 \pm 1.23$ & \\
\hline
\end{tabular}

a $\%$ growth inhibition $=100-\left[\{(\right.$ Celltotal - Celldead $) \times 100\} /$ Cell $\left.l_{\text {total }}\right] ;{ }^{b} C^{2} C_{50}=$ conc. inhibiting $50 \%$ of percentage growth $(n=3)$

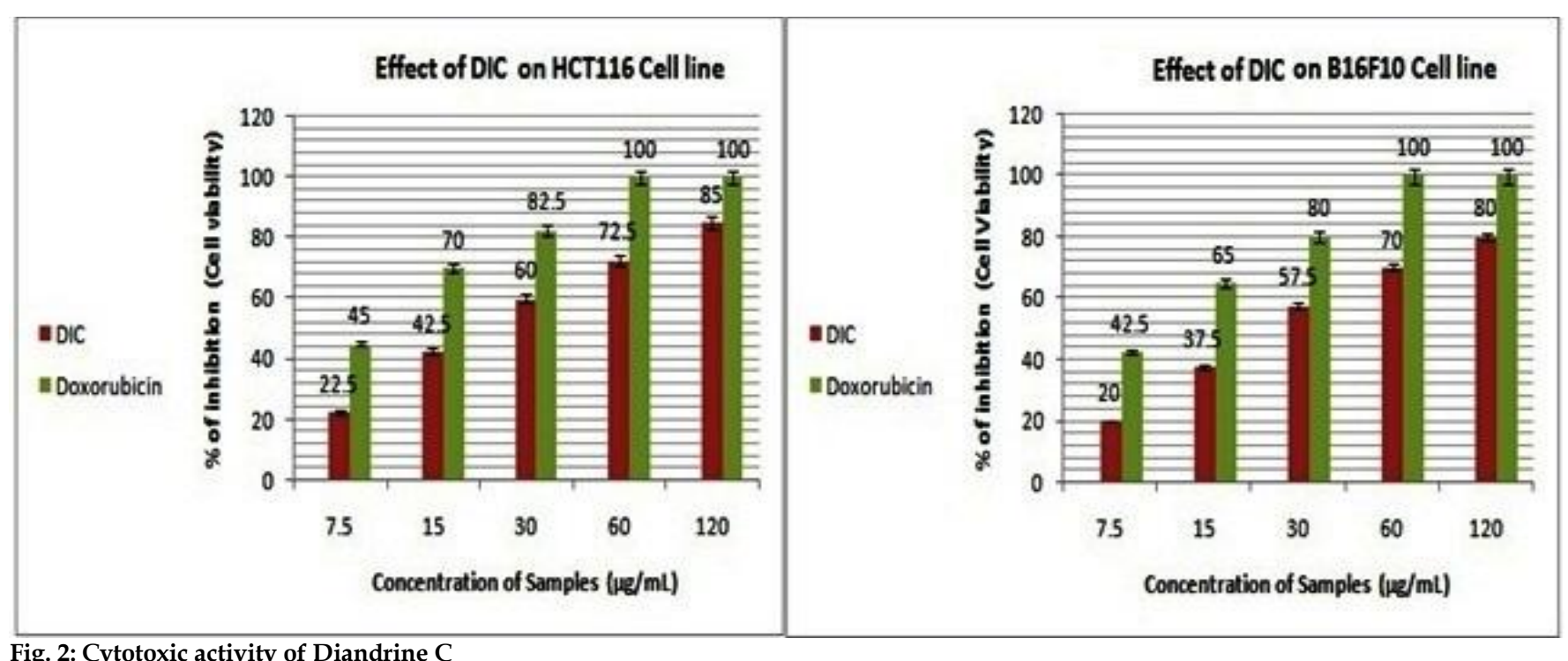

\section{RESULTS AND DISCUSSION}

The synthesized all four natural cyclopeptides, Diandrine A, Diandrine C, Fanlizhicyclopeptide A and Fanlizhicyclopeptide B was accomplished with good yields and pyridine was proved to be an effective base for Cyclization of all the four linear peptides units.
Cyclization of the all linear peptide fragment was supported by the disappearance of absorption bands and confirmation by $\mathrm{IR},{ }^{1} \mathrm{H}$ and ${ }^{13} \mathrm{C}$ NMR and $\mathrm{FAB}$ Mass spectroscopy. 
Kaushal K. Chandrul et al. / Selective Cytotoxic Activity of Synthetic Natural Cyclopeptides on HCT11.

Table 3: Cytotoxic activity data of Fanlizhicyclopeptide A

\begin{tabular}{|c|c|c|c|c|c|c|c|c|c|}
\hline \multirow[b]{2}{*}{ Compd. } & \multirow[b]{2}{*}{$\begin{array}{l}\text { Conc. } \\
(\mu \mathrm{g} / \mathrm{ml})\end{array}$} & \multicolumn{4}{|c|}{ HCT116 } & \multicolumn{4}{|c|}{ B16F10 } \\
\hline & & $\begin{array}{l}\text { Live cells } \\
\text { counted }\end{array}$ & $\begin{array}{c}\text { No. of } \\
\text { dead cells }\end{array}$ & $\begin{array}{l}\text { \% growth } \\
\text { inhibition }^{\text {a }}\end{array}$ & $\begin{array}{c}{ }^{b} C^{2} C_{50} \\
(\mu \mathrm{M})\end{array}$ & $\begin{array}{c}\text { Live cells } \\
\text { counted }\end{array}$ & $\begin{array}{c}\text { No. of } \\
\text { dead cells }\end{array}$ & $\begin{array}{l}\% \text { growth } \\
\text { inhibition }^{\mathrm{a}}\end{array}$ & $\begin{array}{c}{ }^{\mathrm{b}} \mathrm{CTC}_{50} \\
(\mu \mathrm{M})\end{array}$ \\
\hline \multirow{5}{*}{$\begin{array}{c}\text { Fanlizhicyclope } \\
\text { ptide A }\end{array}$} & 120 & $07 \pm 2.21$ & $33 \pm 2.31$ & $82.5 \pm 2.31$ & \multirow{5}{*}{23.136} & $09 \pm 1.87$ & $31 \pm 2.23$ & $77.5 \pm 2.42$ & \multirow{5}{*}{25.35} \\
\hline & 60 & $14 \pm 2.25$ & $26 \pm 2.14$ & $65 \pm 2.14$ & & $16 \pm 2.24$ & $24 \pm 2.19$ & $60 \pm 2.21$ & \\
\hline & 30 & $21 \pm 2.30$ & $19 \pm 2.19$ & $47.5 \pm 1.97$ & & $22 \pm 2.22$ & $18 \pm 2.26$ & $45 \pm 2.23$ & \\
\hline & 15 & $28 \pm 2.26$ & $12 \pm 1.98$ & $30 \pm 2.17$ & & $27 \pm 2.23$ & $13 \pm 2.24$ & $32.5 \pm 2.17$ & \\
\hline & 7.5 & $33 \pm 2.22$ & $07 \pm 1.99$ & $17.5 \pm 2.34$ & & $34 \pm 2.21$ & $6 \pm 2.27$ & $15 \pm 2.19$ & \\
\hline \multirow{5}{*}{ Control } & 120 & 40 & 0 & 0 & \multirow{5}{*}{0} & 40 & 0 & 0 & \multirow{5}{*}{0} \\
\hline & 60 & 40 & 0 & 0 & & 40 & 0 & 0 & \\
\hline & 30 & 40 & 0 & 0 & & 40 & 0 & 0 & \\
\hline & 15 & 40 & 0 & 0 & & 40 & 0 & 0 & \\
\hline & 7.5 & 40 & 0 & 0 & & 40 & 0 & 0 & \\
\hline \multirow{5}{*}{ Doxorubicin } & 120 & 0 & $40 \pm 1.22$ & $100 \pm 1.15$ & \multirow{5}{*}{8.14} & 0 & $40 \pm 1.19$ & $100 \pm 1.14$ & \multirow{5}{*}{8.68} \\
\hline & 60 & 0 & $40 \pm 1.31$ & $100 \pm 1.21$ & & 0 & $40 \pm 1.13$ & $100 \pm 1.14$ & \\
\hline & 30 & $14 \pm 1.13$ & $26 \pm 1.22$ & $65 \pm 1.13$ & & $16 \pm 1.11$ & $24 \pm 1.14$ & $60 \pm 1.12$ & \\
\hline & 15 & $21 \pm 1.21$ & $19 \pm 1.19$ & $47.5 \pm 1.22$ & & $22 \pm 1.16$ & $18 \pm 1.21$ & $45 \pm 1.21$ & \\
\hline & 7.5 & $27 \pm 1.14$ & $13 \pm 1.24$ & $32.5 \pm 1.24$ & & $28 \pm 1.12$ & $12 \pm 1.18$ & $30 \pm 1.23$ & \\
\hline
\end{tabular}

a $\%$ growth inhibition $=100-\left[\{(\right.$ Celltotal - Celldead $) \times 100\} /$ Cell $\left.l_{\text {total }}\right] ;{ }^{b} C_{C} C_{50}=$ conc. inhibiting $50 \%$ of percentage growth $(n=3)$

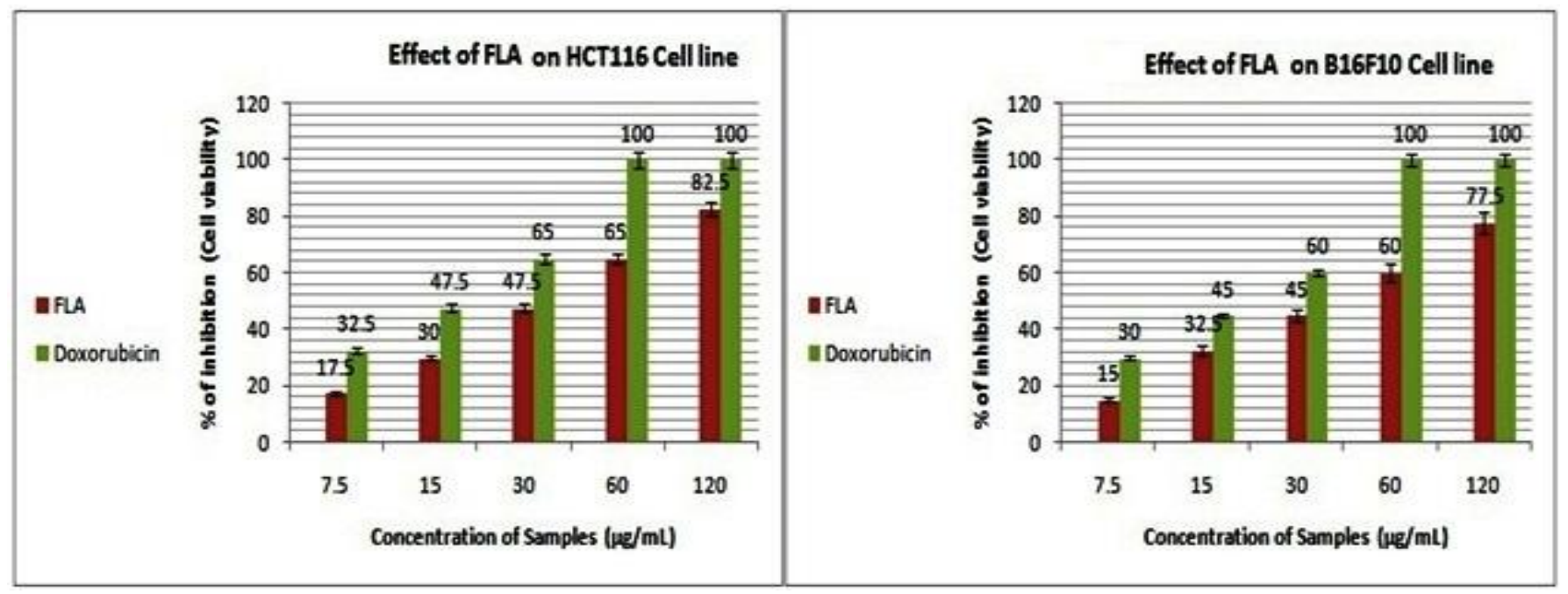

Fig. 3: Cytotoxic activity data of FLA (20)

Table 4: Cytotoxic activity data of Fanlizhicyclopeptide B

\begin{tabular}{|c|c|c|c|c|c|c|c|c|c|}
\hline \multirow[b]{2}{*}{ Compd. } & \multirow[b]{2}{*}{$\begin{array}{l}\text { Conc. } \\
(\mu \mathrm{g} / \mathrm{ml})\end{array}$} & \multicolumn{4}{|c|}{ HCT116 } & \multicolumn{4}{|c|}{ B16F10 } \\
\hline & & $\begin{array}{c}\text { Live cells } \\
\text { counted }\end{array}$ & $\begin{array}{c}\text { No. of } \\
\text { dead cells }\end{array}$ & $\begin{array}{c}\text { \% growth } \\
\text { inhibition }\end{array}$ & $\begin{array}{l}\mathrm{b}^{\mathrm{b}} \mathrm{CTC}_{50} \\
(\mathrm{\mu M})\end{array}$ & $\begin{array}{l}\text { Live cells } \\
\text { counted }\end{array}$ & $\begin{array}{c}\text { No. of } \\
\text { dead cells }\end{array}$ & $\begin{array}{l}\text { \% growth } \\
\text { inhibitiona }\end{array}$ & $\begin{array}{c}{ }^{\mathrm{b}^{2} \mathrm{CTC} \mathrm{C}_{50}} \\
(\boldsymbol{\mu M})\end{array}$ \\
\hline \multirow{5}{*}{$\begin{array}{c}\text { Fanlizhicyclope } \\
\text { ptide B }\end{array}$} & 120 & $09 \pm 0.23$ & $31 \pm 0.32$ & $77.5 \pm 0.28$ & \multirow{5}{*}{25.5} & $08 \pm 0.19$ & $32 \pm 0.28$ & $80 \pm 0.35$ & \multirow{5}{*}{26.05} \\
\hline & 60 & $15 \pm 0.28$ & $25 \pm 0.30$ & $62.5 \pm 0.24$ & & $13 \pm 0.25$ & $27 \pm 0.17$ & $67.5 \pm 0.31$ & \\
\hline & 30 & $22 \pm 0.19$ & $18 \pm 0.29$ & $45 \pm 0.26$ & & $19 \pm 0.13$ & $19 \pm 0.23$ & $47.5 \pm 0.27$ & \\
\hline & 15 & $30 \pm 0.14$ & $10 \pm 0.24$ & $25 \pm 0.28$ & & $28 \pm 0.22$ & $12 \pm 0.29$ & $30 \pm 0.34$ & \\
\hline & 7.5 & $36 \pm 0.15$ & $04 \pm 0.25$ & $10 \pm 0.27$ & & $33 \pm 0.34$ & $7 \pm 0.37$ & $17.5 \pm 0.36$ & \\
\hline \multirow{5}{*}{ Control } & 120 & 40 & 0 & 0 & \multirow{5}{*}{0} & 40 & 0 & 0 & \multirow{5}{*}{0} \\
\hline & 60 & 40 & 0 & 0 & & 40 & 0 & 0 & \\
\hline & 30 & 40 & 0 & 0 & & 40 & 0 & 0 & \\
\hline & 15 & 40 & 0 & 0 & & 40 & 0 & 0 & \\
\hline & 7.5 & 40 & 0 & 0 & & 40 & 0 & 0 & \\
\hline \multirow{5}{*}{ Doxorubicin } & 120 & 0 & $40 \pm 0.01$ & $100 \pm 0.01$ & \multirow{5}{*}{9.23} & 0 & $40 \pm 0.01$ & $100 \pm 0.04$ & \multirow{5}{*}{9.77} \\
\hline & 60 & 0 & $40 \pm 0.01$ & $100 \pm 0.02$ & & 0 & $40 \pm 0.01$ & $100 \pm 0.03$ & \\
\hline & 30 & $12 \pm 0.17$ & $28 \pm 0.21$ & $70 \pm 0.19$ & & $13 \pm 0.11$ & $27 \pm 0.17$ & $67.5 \pm 0.21$ & \\
\hline & 15 & $22 \pm 0.13$ & $18 \pm 0.14$ & $45 \pm 0.17$ & & $21 \pm 0.16$ & $19 \pm 0.19$ & $47.5 \pm 0.24$ & \\
\hline & 7.5 & $28 \pm 0.15$ & $12 \pm 0.27$ & $30 \pm 0.14$ & & $27 \pm 0.12$ & $13 \pm 0.18$ & $32.5 \pm 0.15$ & \\
\hline
\end{tabular}

a $\%$ growth inhibition $=100-\left[\{(\right.$ Celltotal - Celldead $) \times 100\} /$ Cell $\left.t_{\text {total }}\right] ;{ }^{b} C_{C C} C_{50}=$ conc. inhibiting $50 \%$ of percentage growth $(n=3)$

Diandrine A, Diandrine C, Fanlizhicyclopeptide A and Fanlizhicyclopeptide $B$ these all the synthesized cyclopeptides were evaluated for their in-vitro Cytotoxic activity using MTT (3-(4, 5dimethylthiazolyl-2)-2, 5-diphenyltetrazolium bromide) against HTC116 and B16F10 Cellline. The life span was increased for the compounds, when compared to
Doxorubicin for the selected concentration from $7.5 \mu \mathrm{g} / \mathrm{mL}$ to $120 \mu \mathrm{g} / \mathrm{mL}$. The $\mathrm{CTC}_{50}$ value against HTC116 and B16F10 Cellline was calculated for Diandrine A, 20.16 \& 20.21, for Diandrine C, 16.42 \& 17.73 for Fanlizhicyclopeptide A, 23.12 \& 25.35, and Fanlizhicyclopeptide B, 25.5 \& 26.05 respectively. 


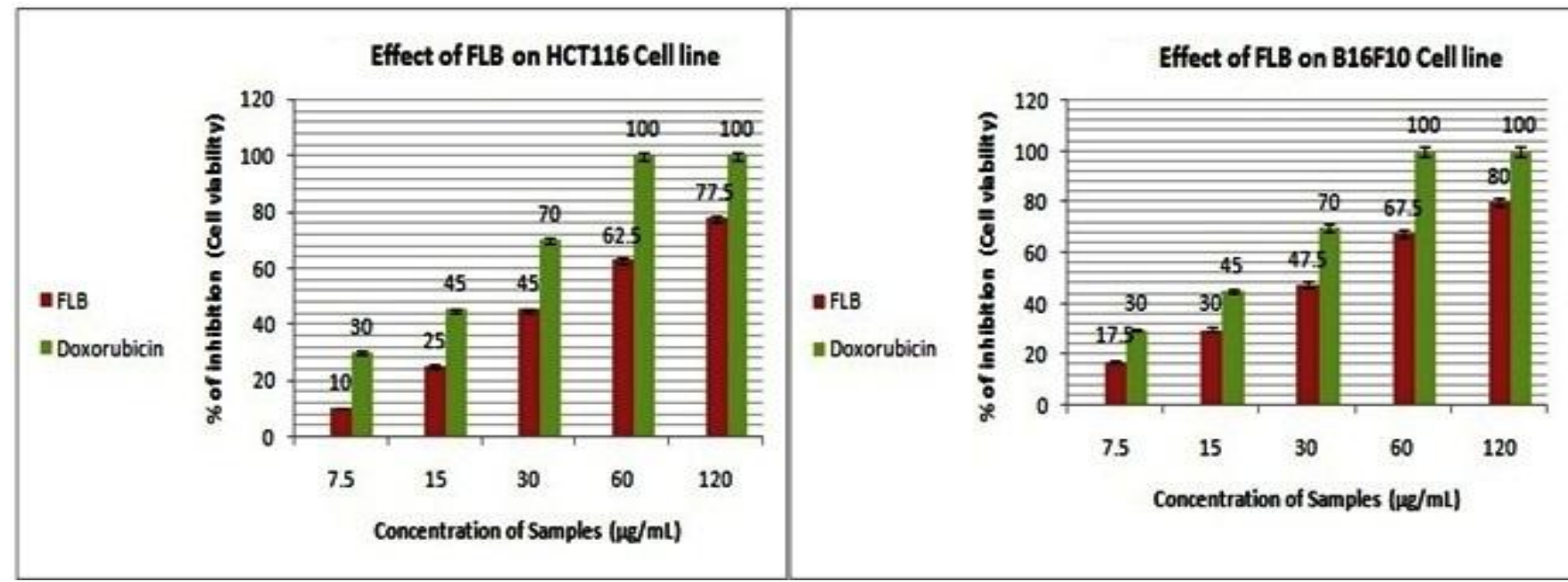

Fig. 4: Cytotoxic activity data of Fanlizhicyclopeptide B

All four synthesized natural cyclopeptides were shows cytotoxic effect against HTC116 and B16F10 Cellline. The cytotoxic activity of these natural cyclopeptides could be due to the presence of bioactive structure.

\section{ACKENOWLEDGEMENT}

We are thankful to Invertis Institute of Pharmacy, Invertis University, Barelly, U.P., provided his facilities for synthesis of these compounds and also thankful to School of Pharmaceutical Education and Research, Jamia Hamdard University for spectral analysis and Deshpanday laboratory, Bhopal (M.P.) for provide place for cell line study.

\section{REFERENCES}

1. Hohtola A. Bioactive compounds from northern plants. Adv. Exp. Med. Biol. 2010; 698: 99-106.

2. Christaki E, Bonos E, Giannenas I, Florou-Paneri P. Aromatic plants as source of bioactive compounds. Agriculture. 2012; 2:228-243.

3. Sasidharan S, Chen Y, Saravanan D, Sundram KM, Yoga Latha L. Exteraction isolation and characterization of bioactive compounds from plants extracts. Afr. J. Tradit. Complement. Altern. Med. 2011; 8:1-10.

4. Daly N, Wilson D, Craik D. Cyclic peptides from plantsand there promice in drug design. Aust. Biochem. 2012; 43:7-9.

5. Hsieh PW, Chang FR, Wu CC, Wu KY, Li CM, Wang WY, Gu $\mathrm{LC}, \mathrm{Wu}$ YC. Selective inhibition of collagen-induced platelet aggregation by a cyclic-peptide from Drymaria diandra. Helv. Chim. Acta. 2004; 87: 57-66.

6. Dahiya R. Cyclopolypeptides with antifungal interest. Coll. Pharm. Commun. 2013; 1:1-15.

7. Chuang PH, Hsieh PW, Yang YL, Hua KF, Chang FR, Shiea J, $\mathrm{Wu} \mathrm{SH}, \mathrm{Wu}$ YC. Cyclopeptide with anti-inflammatory activity from seed of Annona Montana. J. Nat. Prod. 2008; 71:1365-1370
8. Dal PF, Cotugno R, Lepore L, Vassallo A, Malafronte N, Lauro G, Bifulco G, Belisario MA, de Tommasi N. Chemical proteomics reveals HSP70 1A as a target for the anticancer diterpene oridonin in Jurkat cells. J. Proteom. 2013; 82:14-26.

9. Gao SY, Li J, Qu XY, Zhu N, Ji YB. Downregulation of Cdk1 and cyclinB1 expression contributes to oridonin-induced cell cycle arrest at G2/M phase and growth inhibition in SGC7901 gastric cancer cells. Asian Pac. J. Cancer Prev. 2014; 15:6437-6441

10. Wang $\mathrm{H}, \mathrm{Ye} \mathrm{Y}, \mathrm{Yu} \mathrm{ZL}$. Proteomic and functional analyses demonstrate the involvement of oxidative stress in the anticancer activities of oridonin in HepG2 cells. Oncol. Rep. 2014; 31:2165-2172.

11. Liu $\mathrm{Y}$, Liu JH, Chai $\mathrm{K}$, Tashiro S, Onodera S, Ikejima T. Inhibition of c-Met promoted apoptosis, autophagy and loss of the mitochondrial transmembrane potential in oridonininduced A549 lung cancer cells. J. Pharm. Pharmacol. 2013; 65:1622-1642.

12. Liu JJ, Huang RW, Lin DJ, Wu XY, Peng J, Pan XL, Lin Q, Hou M, Zhang MH, Chen F. Antiproliferation effects of oridonin on HPB-ALL cells and its mechanisms of action. Am. J. Hematol. 2006; 81:86-94.

13. Dahiya $R$, Singh S. First Total Synthesis and Biological Potential of a Heptacyclopeptide of Plant Origin. Chin. J. Chem. 2016; 34:1158-1164.

14. Dahiya R, Singh S, Sharma A, Chennupati SV, Maharaj S. First Total Synthesis and Biological Screening of a ProlineRich Cyclopeptide from a Caribbean Marine Sponge. Mar. Drugs. 2016; 14(228):1-14.

15. Dahiya R, Singh S. Synthesis, Characterization, and Biological Activity Studies on Fanlizhicyclopeptide A. Iranian Journal of Pharmaceutical Research. 2017; 16(3): 1178-1186

16. Dahiya R, Singh S. Synthesis, characterization and biological screening of Diandrine A. Acta Poloniae Pharmaceutica \& Drug Research. 2017; 74(3):873-880.

17. Dahiya R, Singh S. Toward the Synthesis and Pharmacological Screening of a Natural Cycloheptapeptide of Plant Origin. Nat. Prod. Commu. 2017; 12(3):379-384.

18. Dahiya R, Singh S, Kaur K, Kaur R. Total synthesis of a natural cyclooligopeptide from fruits of sugar-apples Bull. Pharm. Res. 2017; 7(3):151-158. 